\title{
Russian Learned Elite to Search New Development Purport
}

\author{
Paul L. Karabushenko
}

Arushan A.Vartumyan

Tatiana A. Shebzukhova

Igor N. Bobrovsky

Federal State Autonomous North Caucasus Federal University

Doi:10.5901/mjss.2015.v6n5s2p529

\begin{abstract}
According to the post-industrialism theory, scientific knowledge will be the most valuable thing and the meritocracy (the learned elite) will be the main steering force in the information society. Today we live in the scientific knowledge world we exist in the information flow penetrating us. This is high-quality knowledge that a human being depends on in an increasing extent. Thus, the role of the learned elite increases manifold. The learned elite produce knowledge, the society and authority produce information. Knowledge belongs to ascience, information is possessed by the people outside. The cult of scientific knowledge is basic for the present-day learned elite. Geniuses of science with their authority have replaced the sanctified people's power. However, the there is no conflict between the clerical and the secular world owing to delimitation of spheres of influence and authority.
\end{abstract}

Keywords: scientist, learned elite, meritocracy, post-industrialism, learned elite classification, authority, intellectual property, elite education, personality, creative work, personalism

\section{Introduction}

The theme of the learned elite is rather seldom discussed in elitological science. Meanwhile the role of the learned elite itself in the development of mankind is hard to underestimate. Whatever the human race possesses is only owing to science and in first place, to the outstanding scientists who had made their fundamental discoveries for the sake of the mankind.

While stating the learned elite as an object of our investigation, we focus our subjectattention on the characteristic features of the Russian elite since we have an opportunity to conduct an overt observation and give an objective expertise evaluation. While evaluating the learned elite we will adhere to the position of philosophic thinking originality specified by Plato and A. Toynbee's conception of the creative minority's historical responsibility searching for the responses of the epoch's challenges.

Pursuit of the new purports in culture and civilization development has always been fundamental for the creative minority looking for the adequate answer to their epoch's challenges. (Toynbee A.. 2012). The challenge of this time is that it is at the meeting-point of the historical epochs to be late industrialism and early post-industrialism. This is vividly seen in the dynamics of scientific community development, especially among the representatives of the learned elite.

It is science that to a larger extent than politics is pinned hopes and responsibilities on for the evolvement of the new post-industrial reality. The political elite for the first time in history appears to be not a leading but a driven force. The formula of this society is: first science comes, thenpolitics does. This principle is applied to the Russian reality. The last 300 years Russia's wealth grew owing to Siberia; the following 300 years Russia is to grow in brains and in the first place, in its learned elite's intellect. However, the division into Russian and foreign scientists will look as anachronism since the learned elite is an asset of all the mankind.

This article deals with the analysis of the current state of the Russian learned elite, revelation of the obstacles they face carrying out their professional activities. The subject of this study is the Russian learned elite and theemphasis is put onto the analysis of the crisis developments having taken shape in the conditions of the late industrial society in the conventional way of learned community functioning. The general hypothesis of our investigation is the idea that in the conditions of industrial society transformation into a post-industrial one and transfer from "mass rebellion" to "elite rebellion", the conflict between the oligarchical and meritocratical trends in elite education, culture and science will be 
aggravated.

\section{Research Methodology}

Learned elite as a learned society.Great Plato once wrote that in the existing world of ideas those people feel better who have philosophic (to be read as scientific) habit of thought (State. 484b). The first academician explained that by the mankind's urge to good. Everybody strives for the best levelling the worst. However, the worst as a weed grows everywhere while the best always requires cultivation. Culture is the thing, which elevates a human being over his/her nature sin.

So, what is learned elite? First of all it is an outstanding personality not just having found himself/herself in science but having made certain achievements in it. Elite consciousness'schanged under the influence of education and upbringing mass consciousness where the idea of the personality was put in the first position and affirmed as a basic value. The presence of the elite always entails adoption of hierarchy. In this case, it is intellectual hierarchy. Such elite is characterized by the critical, independent and constructive thinking. The ability to resist effectively the pressure of masses and widespread public interests is of special value. The modern mass culture calling is to transform the greatest achievements that have been accumulated in culture and owing to this to self-affirm of its own standards. It is this ability to resist the general mass trend that the elite personality is summoned to do. The elite does not endure periphery, it pursuits Zeitgeist. To be eternal Zeitgeist is its main goal.

\section{Analysis Result}

The learned elite is composed of creators of intellectual values, outstanding analysts and empiricists recognized by the professional community. One can find the collocation of "super intellectual elite" in the scientific literature. Prestigious international prize laureates are referred to that kind of elite. The learned elite is a constant variable selected minority whose superiority in scientific knowledge is absolute, recognized and authoritative. The learned elite are the mankind's selected minds; they are, as a rule, a small cohort of those who have contributed a lot in the scientific activity development. The learned elite comprise the scientists whose professional accomplishments have importance, higher value and superiority recognized by the scientific community. Scientific consciousness is an exact reflection of the objective reality, which it is focused on. Plato in his day said about this asserting that a scientist is the one was able to affirm his intellect's harmony through the Universe harmony contemplation (Timaeus, 90d).

The notion of the learned elite has several synonyms: spiritual elite, intellectual elite, meritocracy, knowledge elite, aristocracy of intellect, etc. The main point of those meanings is that all point to that narrow layer of people who are engaged in producing intellectual property. (Toynbee A.Kokhanovsky V.Leshkevich, T.Matyash, T.Fatkhi, 2004).The learned elite possess one essential and indubitable feature to be intellectual elitism gained as a result of the maximum use of all their meritocratic qualities.

Among the intellectuals, the selection takes place in the sphere of higher mental activity. The most capable, active, successful people are selected in the elite and untenable candidates are discarded. Thus, the selection of the learned elite is always of open meritocratic type with its pluralism and relativity. Unlike the political elite, the learned one (cultural as well) is formed through activating and foregrounding of a person's personal qualities. Therefore, those elite to a larger extent corresponds to the epithet of the cream of society or nation's honor.

There are several important things about the definition of the learned elite essence. Usually a set of traits and qualities, which help to identify the elite group is singled out. These criteria include the following characteristics: 1) learned elite jointly with artistic one is classified as so-called "uncontrolled elite" who due to some reasons have to cooperate with the ruling (political) elite. (V. Pareto); it is the advanced elite of the civil society; 2) the learned elite's subject possesses originality (independence) in the highest degree to prove the scientist's greatness (W. Ostwald, $\mathrm{H}$. Selye); 3) those contributing most in the scientific knowledge system: scientists having made fundamental discoveries, having created scientific theories to be integrated in and being the integral part of the scientific world view; 4) objective recognition: the learned elite are those who according to their personal qualities gain the highest rank in their scientific activities and in the novel knowledge, in particular (S.A. Kugel, I.A. Maizel); 5) the learned elites are scientists possessing the confirmed world investigation level (B.G. Saltykov); 6) recognizing the learned elite takes place not in the social and political sphere but in the information and cognitive one, at the level of scientific accomplishments and knowledge; 7 ) in the horizontal plane there are two types of the learned elite: creative and administrative ones (Osipova N., 1998).

Distinguishing the intellectual and personal principle as a major characteristic of the learned elite subject is a 
retrospective process (through turning from the vital professional scientist's life to his/her origins, to the phase of his/her prominent capabilities formation) (Osipova N., 1998).

The specialists consider the unified scale of values of the scientific outcomes to have to ranks: 1) the highest, which is conferred on to the problem and the anticipated outcome when this outcome is likely to discover new rules of the object being investigated, new phenomena, theories, etc.; 2) the second rank of the scientific value is characterized by deepening and expanding knowledge of those objects in which first rank scientific outcomes have been obtained (it is searching of new properties and interrelations in the earlier discovered laws, phenomena, new inventions, etc.) and 3) the third rank is searching new areas to apply well-known ideas and solutions, expanding a discovery application sphere considering both positive and negative accompanying factors(Osipova N., 1998).

This elite includes only those who can outscore the "passing grade". The reason for scientists' classification is the aggregate of their scientific achievements, the evaluation of the scientific outcomes importance by the learned society.

As the required attributes of the learned elite "subjectness" the following formal indicators are proposed: (1) election of some scientist for the post of full member, corresponding member, honorary academy member, member of research institutions and societies; (2) awarding scientists with prizes and medals for research activity; (3) giving biographic data in the reference books and encyclopedias; (4) scientists' participation in editorial board work, highly scientific editions; (5) high citation index of a scientist's publications by the world scientific community members, (Leshkevich T., 2001)

The specialists acknowledge that when characterizing the classification of the intellectual elite, such categories as "Promethei" and "syntheticists" should be addressed. "Promethei are the creators of new notions, theories, ways of thinking. "Syntheticists" tend to make general discoveries. The most demonstrative indicator of the learned elite except citation index, scientific titles and prizes is the spontaneous conferring the author's name to the discovery or theory made by him". (Leshkevich T., 2001).

There is an opinion that the inherent in the scientists "will to knowledge" is just a kind of "will to power" typical to the politicians. It is by these two types of will that the considerable differences between the ruling (political) and non-ruling (civil) elite are found, the latter (the civil society elite) playing a larger part in the course of transformation of the industrial society into post-industrial one. If social-political elite is that part of the population who appropriate the maximum amount of material wealth, the learned elite is formed through the permanent production i.e. qualitative increase in the scientific knowledge.

\subsection{Learned elite as an expert community}

The learned eliteis not just an expert community which produces this quality for the first time but also people who can evaluate other people's achievements. The expertise itself evaluates quality. The learned elite have specialized professional (i.e. esoteric) language comprehensible only by the professionals (the "dedicated"). The main value of the learned elite is the quality of the scientific knowledge and a scientist's ingenuity. The system formed by them is selfsufficient and it possesses elite energy (the ability to influence other people; to form a managerial impulse). Such selfsufficiency is not only autonomy of the project performed the scientists but also an evaluation of the scientist's personality as a "thing in itself" («Ding ansich»). Elitology of a science deals with decoding of some elite personality.

The science is pushed ahead by those elite personalities who are capable of going into the mysteries of the environment and human being's internal mysteries. Generally, we can say that the learned elite is the "engine of a science". The intellectual elite's unique capabilities were paid attention to by the ancient Greek philosophers (Heraclitus, Plato, Aristotle, Seneca). They mentioned that the people with philosophic mindset, as a rule, see what others (common people) unable to see. "Philosophers are people capable to perceive what is eternally identical to itself while other people cannot do it and ...[thus wander]among many various things and therefore they are not already philosophers"(State, 484b).

It was noted that where the modern political elites lose connection with the expert learned community and rely only on military and economic resources, political measures result in conflicts rise and tension. Thereupon, political scientists repeatedly paid attention to the political leadership fall, "retirement" of those political elites who ruled the world in 19802000 s and could give the adequate assessment to the current events. New elite regeneration tends to use the old technologies, which malfunction more and more often and do not result in the desired effects. For instance, for the elderly generation of geopolitical gurus (Z. Brzezinski, S. Huntington, F. Fukuyama) it is more difficult to build their previous scientific achievements in the new post-industrial realities. The new epoch needs new teachers of mankind to come from the scientific milieu, from the learned elite, to be more exact. We are not in the position to speak about the exact time of the meritocracy's taking power. We cannot know about it but we feel it with every year coming. The oligarchical 
tendencies are still strong in the world. To keep their monopoly onto the power, they will resist to this inevitable transformation. The meritocracy will certainly come and the leading countries can work in this direction proactively. However, there are countries which can face some severe difficulties in this connection, Russia including.

Russia's authorities have always used the learned elite as a means and very seldom treated it as a goal. The authorities remembered about the learned elite only when they had to solve complicated political problems. Such relations can be called paternalistic. The empire wanted to control everything, including science development not to permit free-thinking among the most intelligent Russia's class. At the same time, the authorities seldom paid attention to the advice of its learned expert community, especially what concerned social and humanitarian knowledge. If in the USA geopolitics (as a science) and the authority's foreign policy interact closely and support each other, in present-day Russia we see a vivid gap between these two professional communities, what, undoubtedly, represents a threat for the state's national security.

\subsection{Pro et contra of the modern Russian learned elite}

Dialectical consideration of the issue on the quality of the modern Russian learned elite is sure to reveal its positive and negative features.

A successful regeneration of the scientific potential by the learned elite can be referred to the positive characteristics. This is clearly seen at the background of so-called brain drain, which made a severe impact in the 1990s when a large number of the Russian specialists left the country for good.

A weak integratedness into the world scientific community is seen as a drawback of the Russian learned elite (due to poor knowledge of the foreign languages and fragmentary academic mobility), the lack of a reliable channel for dialogue and communication with its political authorities, scanty state funding of the scientific projects and extremely low level of scientific marketing. It should be emphasized that Russian business community treats education and science from the consumer's point of view and they do not wish to contribute to their development.

Well-established international cooperation in the tsarist's time was completely destroyed by the Soviet authorities to be jealously controlling the Soviet scientistsrelations with the world community. The isolation policy cut the Soviet learned elite from the foreign one. It is true that at that time the Soviet science had had its outstanding scientific achievements and scientists (A.I. Ioffe, A.F. Losev, V.I. Vernadsky, P.L. Kapitsa, S.P. Korolyov, L.D. Landau, M.M. Bakhtin). The world community could only guess at their existence. A real case can well characterize how the Soviet authorities treated the learned elite. In 1958, the Nobel Committee requested the USSR Government on nominating S.P. Korolyovfor the Novel Prize. In response to the Nobel Committee N.S. Khrushchev stated: "all Soviet people excelled in the Satellite work and all of them deserved a reward". S.P. Korolyov was offended but he did not show the offence publicly. (Khrushchev deprived Korolyov of the Nobel Prize .07.12.2014)The secrecy about the chief designer of space hardware was withdrawn only after his death in 1966.

Transition to post-industrialism can be referred to as a grave challenge of the contemporary history. Howis the learned elite prepared to this transition? How can they exhibit their leadership qualities and be at the head of this process? This transition reinforces the confrontation of the oligarchical and meritocratic trends. (Ashin G., KarabushchenkoP., 2011)Russia possesses financial resources but they cannot be compared with the funds owned by the Anglo-Saxon universities from the Top-10 (by the opinion of QS). Therefore, there is an inevitable requirement to reinforce and expand the meritocratic values.

The obvious weakness of the learned elite is not always adequate perception of it by the Russian society. In consequence of the egalitarian mental set and paternalistic attitude to the intellectual elite as a whole, inherent in Russian social consciousness, various strata of society have conservative (precautious) estimations. The mass consciousness and mass culture see the intellectuals and learned elite as something alien, foreign and sometimes even hostile to their standards and mode of life. Hence, on the one hand there is obvious respect to brainwork people and on the other hand, some distrust as a self-protection measure against the possible "aggression" on their party ("it is unknown what these scientists will devise"). The reason is that the asset being produced by the intellectuals differs a lot from the one that the societal majority is used to dealing with.

Another important thing we cannot omit dwelling upon is so-called Matthew effect, according to which, the recognized scientists gain new benefits (prizes, awards, citation) much easier than their unrecognized colleagues. (Leshkevich T., 2001).Excessive reverence for the authority is a sign of a scholastic mindset. New scholastics' coming into being and reinforcing is threatening the Russian science. This trend will only gain strength in case the scientific elite transforms into the meritocracy unsuccessfully.

The scientific community of Russia is quite critical to the higher school reform initiated by the Government. So- 
called Bologna process causes resentment (especially in Russia's regions) due to insufficiently considered and forcible policy of the reformers. Much attention is paid to the questionable benefits of reforming. The lack of public discussion of this issue is another negative sign of academic development in Russia.

The representatives of the Russian learned elite express discontent with the current foreign ranking score of the elite. The thesis proposed is that among the ranking score systems those of the English-speaking countries prevail and high-prestige international prize committees members adhere to Russo phobia opinion. In particular, criticism of the Nobel Committee is growing due to its obviously subjective and politically loaded USA leaning (especially after A. Gore and B. Obama's awarding with the Nobel Prize). This criticism reflects the former Soviet negative attitude to the Nobel Prize to have been the result of the ideological confrontation of communism with the imperialistic western countries. ${ }^{1}$

In 1990-2000s, the Russian learned community saw grave pressure from so-called "alternative sciences" (quasi science and quasi scientists: ufology, astrology, parapsychology, cryptozoology, etc.). RF Academy of Sciences concerned with this fact has established the Panel Committee to contend against pseudo-science and scientific investigations falsification. The Panel draws a conclusion that over the last years about 120 self-styled academies have been established. Even anti-scientific "research" institutes have been founded, the mass media popularizing the unconcealed misinformation. (Science - Antiscience: confrontation chronicle, 2001)

Excessive parochial mentality (regional restraint) of some learned communities can also be referred to the drawbacks. The majority of the learned elite live in the cities and metropolises. Localization in the conditions of information globalization shows scantiness and absence of demand for the regional scientific products. We can often hear of "capital snobbery", "provincial backwardness", low-ranked professional standards, scholastic views, dogmatism and falsification (Karabushchenko P., Lebedeva I. , 2013). The criticism is quite reasonable but it is too often is applied for speculation.

Plagiarism has become a sort of perdition for the Russian science of the beginning of the $21^{\text {st }}$ century. This phenomenon has been seen more often due to the civil servants' wish to be awarded with scientific degrees. In January 2013 an alternative organization "Dissernet" Free Network Community composed of professional scientists working in various spheres, journalists, civil activists, volunteers was set up. "Dissernet" core activity is in conducting expert evaluation of the dissertations having been defended in Russian research and educational institutions. According to the activists whole "dissergate corporations" were established in Russia to produce and defend "scientific" dissertations. The State Commission for Academic Degrees and Titles counter charges in incorrect and formal evaluation of the thesis work.

\subsection{The meritocracy and post-industrialism}

At the beginning of this paper, it was stated that we perceive larger impact of the requirements and standards of the postindustrial society with its well-developed information constituent. The post-industrialism theory promises us the real revolution in the sphere of public thinking when values of information society are established. (M. Young, 1958, D.Bell, 1976, A. Toffler, 1970, etc.).

The learned elite is a community with subtle sense of dignity and freedom. The western politicians understood this many years ago. The Russian politicians started to understand this as well (Russia is an eastern part of the western world thus, the western ideas come here with a little delay but still faster than in the countries with eastern (purely Asian) mentality.

From the classical personalize view point (N.A. Berdyaev, E. Mounier), freedom is a personality's basic attribute. This refers to a larger extent to the learned elite subjects. Only such people will possess absolute freedom in the information society. Their freedom is the maximum convergence of meritocracy and anarchy (in the manner of scientific anarchism conception). Only a scientist will be anarchically free and will possess social and cultural self-sufficiency. Science will be the main warranty of his/her freedom and independence from the political elite power. That is why the meritocracy is the main aim of the present-day learned elite development. Therefore, the question arises: to what extent will the previous patterns of the learned elite development correspond to the new conditions of post-industrialism? The main problem that science is to resolve is the problem of meritocratic self-sufficiency(Karabushchenko P., Lebedeva I., 2013).

${ }^{1}$ For example, at the Physical and Mathematical Sciences office session of USSR Academy of Science son November 1, 1955 they announced the rejection to nominate the Soviet scientists for the 1956 Nobel Prize (clause 19 of the Minutes). The reason for that decision was as follows: "This Prize is not considered to be the international one owing to the fact that in due course time the Nobel Committee saw no rationale for awarding culture and science workers of this country with this Prize (D.I. Mendeleev, L.N. Tolstoy, A.P. Chekhov, M. Gorky)". [See: 3] 
The international practices that the prestige of any state nowadays depends more on the intellectual potential of its citizens and in the first place, on the learned elite. Moreover, in the forthcoming industrialism epoch, the role of the meritocracy is growing in the wake of this trend rising. Information security, self-sufficiency is already a key factor of the state sovereignty in the post-industrial world. The society cannot attain this goal without science and scientists. The political elite is no longer the "prophet" who the societal majority follow. It is the reason why politics goes to the background giving way to science.

Undoubtedly, the learned elite will play the leading part in the knowledge economies which is understood as the highest stage of development of post-industrial and innovation economy. The main factors of development of such economies is knowledge and human assets and the process of development is based on the quality enhancement in every sphere connected with it. The learned elite creative products can be used by all the mankind. The learned elite cannot be nationalized when the democratic values and liberal institutions dominate. Only totalitarian systems set monopoly on their learned elite activity.

\section{Concluding Remarks}

Today advanced technologies make up the basis of breakthrough scientific projects. The function of high technologies is to promote progress, to control scientific and technological revolution. It is the learned elite who carry out creative management of high technologies. Since high technologies are the most science intensive industries, the role of the learned elite in those brunches will also be large. At the same time, the share of the authority elite in those projects will steadily decrease giving way to the learned elite domination. As we know, the invariant "height" sign (prestige, importance, elite) of some technology is the degree of a human being's participation in the technological process. The less a human being is engaged in the process, the higher the technology is; the higher the technology, the more learned community's labors spent on the technology creation.

The new sense in the learned elite development is creating conditions to develop open meritocratic communities based on the liberal and democratic values. Unfounded appeals to advanced technologies development are to be supported by well thought-out state policies in the sphere of science and higher education and also by expanding business participation in research projects. The lack of business involvement in funding scientific projects and inadequate control of the civil society make the Russian learned elite financially vulnerable.

To conclude everything said above, we must note that the meritocratic prospects promise good opportunities connected with the new contract terms with the authorities. The meritocracy is not a simple form of new learned elite's work arrangement but it also a special mind condition. Creative work is becoming the main (fundamental) value of objective reality when crime against creativity will be considered to be crime against all the mankind.

\section{References}

Ashin G.K. Elitology: history, theory, contemporaneity .Monograph. M.: MGIMO (U), 2010. - 600 p.

Ashin G.K., KarabushchenkoP.L. Oligarchialand Meritocratic Trends in Present-day Elite Education Evaluation // Elitology Issues: philosophy, culture, politics. V.7. 2011. P. 10-18.

Bell D.The coming of post-industrial society: a venture in social forecasting. 2nd ed. N.-Y.: Basic Books, 1976.- 507p.

Blokh A.M. "Nobiliana" of Dmitry Mendeleev // Priroda. No. 2, 2002.

Elitology: Encyclopedic Dictionary. / Edited by prof. P.L. Karabushchenko. M.:Econ-inform, 2013. - 618 p. (77.5 sheets)

Karabushchenko N.B. Elite Psychology: a myth or reality (historical and psychological foundations). Monograph. - Germany: Lap Lamber tAcademic Publishing, 2011. - 251 p.

Karabushchenko P.,Lebedeva I. Meritocracy as a synthesis of elite education and post-industrialism // European Applied Sciences. No.1, 2013, pp.232-235.

Karabushchenko P.,Lebedeva I. The Elite and Falsification // Modern socio-political processes in Russia, Europestates and in the World. Stuttgart, 2012.pp.199-206.

Khrushchev deprived Korolyov of the Nobel Prize .07.12.2014. - [Electronic resource] - accessed at :http://www.rb.ru/inform/31217. htmlTitle from the screen. Russian.

Kislitsyn S.A. The Leaned Elite in the Political power System. M.: LKI, 2008. -228 p.

Kokhanovsky V.P., Leshkevich T.G., Matyash T.P. Fatkhi T.B. Philosophy of Science Fundamentals. Rostov-on-Don: Fenix, 2004. $608 \mathrm{p}$.

Leshkevich T.G. Philosophy of Science: traditions and innovations. M. PRIOR Publ. House, 2001. - 428 p.

Lipchanskaya I.V. Genesis of the Learned Elite: social and philosophical analysis: Candidate of Philosophy dissertation: 09.00.11. Rostov-on-Don, 2008. - 195 p.

Osipova N.G. The Leaned Elite // Russian Sociology Encyclopedia /Edited by academician of RAS, prof. G.V. Osipova, M.: Publishing 
Group NORMA-INFRA.M, 1998. $-672 \mathrm{p}$.

Science - Antiscience: confrontation chronicle // Issues of history, nature science and technology, 2001, No. 4.

Toffler A. Future shock. N.-Y.: Random House, Curtis Brown, Ltd. 1970. - 558p.

Toynbee A.J. A Study of History: collected articles / Trans. from English by E.D. Zharkova. Rolf, 2001. - 640 p.

Toynbee A.J. Personality Role in History. / Trans. from English. M.: Astrel, 2012. - 222 p.

Young M. The Rise of the Meritocracy: 1870 - 2033: An Essay on Education and Equality. London, Thames and Hudson.1958.- 382p. 